\title{
Isolation and characterization of a novel serine threonine kinase gene on chromosome 3p22-21.3
}

Received: October 26, 1998 / Accepted: November 30, 1998

\begin{abstract}
Through large-scale DNA sequencing of a genomic region on chromosome 3p22-p21.3, we isolated a novel gene encoding a 527 -amino-acid protein. Its 18 exons spanned a genomic region of about 90 kilobases, and the 4536-nucleotide cDNA contained an open reading frame of 1581 base pairs. The gene was expressed in all 16 human tissues examined by Northern blotting. The amino acid sequence of the predicted protein was $39 \%$ identical to that of human SOK1 (Ste20/oxidant stress response kinase-1), a molecule that is activated by oxidative stress. In view of its significant similarity to SOK1, we suspect that the novel gene, which we named $O S R 1$, is a member of the SOK family of kinases in terms of function.
\end{abstract}

Key words Chromosome $3 p$. Serine threonine kinase . Oxidant stress $\cdot$ Genomic structure

\section{Introduction}

To investigate candidate loci containing putative tumor suppressor genes, we earlier undertook detailed deletion mapping of the short arm of chromosome 3 in a large number of cancerous tissues from lung, uterus, and kidney. That study identified three commonly deleted regions, at 3pterp25, p22-p21.3, and p21.1-p14 (Yamakawa et al. 1991; Hibi et al. 1992; Yokoyama et al. 1992). Subsequent analysis disclosed homozygous deletions at a locus within one of the commonly deleted regions (3p22-21.3) in several lung cancer cell lines (Yamakawa et al. 1993). Since at least one putative tumor suppressor gene was likely to be present in the homozygously deleted region, we further analyzed one

M. Tamari · Y. Daigo · Y. Nakamura $(\bowtie)$

Laboratory of Molecular Medicine, Institute of Medical Science, The University of Tokyo, 4-6-1 Shirokanedai, Minato-ku, Tokyo 108-8639, Japan

Tel. +81-3-5449-5372; Fax +81-3-54495433

e-mail: yusuke@ims.u-tokyo.ac.jp

Y. Nakamura

Department of Genome Analysis, Cancer Institute, Tokyo, Japan of those cell lines and defined the size of the deletion, which was almost $700 \mathrm{~kb}$. The normal genomic sequence from which these 700 kilobases had been deleted was included in a YAC clone, Y936C1 (Murata et al. 1994). To identify genes that are normally present within that region, we have been performing a large-scale analysis of genomic DNA sequences in the vicinity. DNA sequencing and subsequent screening for cDNAs initially disclosed four genes: transGolgi p230, integrin aRLC, HYA22, and a novel gene whose predicted product revealed a high degree of homology to villin (Ishikawa et al. 1997a). Although these four genes were considered to be candidate tumor suppressors for lung and renal cancers, on the basis of their locations within the deleted region, we were unable to find any somatic alterations in any of the primary tumors we examined. However, as the homozygous deletion may have exerted a positional effect by influencing the expression of genes in the near vicinity, we extended the DNA sequencing effort beyond the limits of the 700-kb deleted region. In that effort we located five genes ([human activin receptor type IIB, OCTL1, OCTL2, XYLB, and PLC 1 (phospholipase C delta 1)]) lying distal to the homozygously deleted region (Ishikawa et al. 1997b; 1998; Nishiwaki et al. 1998; Tamari et al. 1998). We now report the identification of a novel serinethreonine kinase gene in the region under investigation.

\section{Materials and methods}

Sequencing of cosmid DNAs and computer analysis of genomic DNA sequences

Four cosmid clones $(581,576,425$, and 566) were fragmented by sonication; 1.5 - to $6.0-\mathrm{kb}$ fragments were recovered and subcloned into pBluescript IISK(-) cloning vector (Stratagene, La Jolla, CA, USA). Plasmid DNAs were isolated from 300 randomly chosen subclones. To confirm the insert sizes and to eliminate clones that contained cosmidvector sequences, plasmids were digested with EcoRI and XhoI, electrophoresed on $0.8 \%$ agarose gels, and analyzed 
by Southern blotting with ${ }^{32} \mathrm{P}$-dCTP-labeled cosmid-vector DNA as the probe. Clones containing human genomic DNA were sequenced with the Dye Terminator Sequencing FS Ready Reaction Kit (Applied Biosystems, Foster City, CA, USA), using T3 or T7 primers and an ABI PRISM 377 DNA sequencer (Perkin-Elmer corporation, Norwalk, CT, USA). DNA sequences were assembled using the ABI Assembler computer software.

cDNA cloning, homology search, and determination of exon-intron junctions

The assembled DNA sequences were analyzed with a computer program (GRAIL 2; Xu et al. 1994) that predicts which sequences might be transcribed. DNA fragments were scored as "excellent", "good", or "marginal" in this context. Using these possible exonic sequences, we performed exon-connection experiments (using reverse transcriptase (RT)-polymerase chain reaction-(PCR)) and screened cDNA libraries. One microgram of poly(A) RNA from human skeletal muscle (Clontech, Palo Alto, CA, USA) was reverse transcribed for single-stranded cDNA, using oligo(dT)15 primer (Boehringer Mannheim, Mannheim, Germany). RT-PCR was carried out in a 20- $\mu$ reaction mixture at $94^{\circ} \mathrm{C}$ for 2 min for initial denaturing, followed by 35 cycles of $94^{\circ} \mathrm{C}$ for $30 \mathrm{~s}, 55^{\circ} \mathrm{C}$ for $30 \mathrm{~s}$, and $72^{\circ} \mathrm{C}$ for $30 \mathrm{~s}$, in a Gene Amp PCR system 9600 (Perkin Elmer Cetus, Norwalk, CT, USA). Each amplified fragment was subcloned in pT7-BlueT (Novagen, Madison, WI, USA); nucleotide sequences were determined with the ABI PRISM 377 DNA sequencer. A total of $1 \times 10^{6}$ clones from a human skeletal-muscle cDNA library (Clontech) were screened with $\alpha-{ }^{32} \mathrm{P}-\mathrm{dCTP}$-labeled cDNA fragments that had been isolated by the exon-connection experiments. The amino-acid sequence of the predicted protein was analyzed with the FASTA program (The Genome Net Database service, Japan (http:// www.genome.ad.jp)) to detect homologies with known proteins. Exon-intron junctions of the gene were defined by comparing cDNA sequences with genomic sequences.

Northern-blot analysis with cloned fragments

Northern blot experiments were performed using human multiple tissue Northern blots I and II (Clontech). The cDNA fragments were labeled with $\alpha-{ }^{32} \mathrm{P}-\mathrm{dCTP}$ by random priming. Membranes were prehybridized and then hybridized according to the manufacturer's protocol. Washed membranes were autoradiographed for $24 \mathrm{~h}$ at $80^{\circ} \mathrm{C}$.

Single-strand conformation polymorphism (SSCP) analysis

We performed SSCP analysis to detect alterations of the novel gene in DNAs isolated from human lung cancer tissues. Tumors and corresponding non-cancerous tissues were obtained after informed consent was given, from 60 patients with primary lung cancers who had undergone surgery at the Cancer Institute Hospital, Tokyo. RNAs extracted from these carcinomas served as templates for the RT-PCR. The coding region was divided into six segments, each of which was amplified separately, using end-labeled primers. For the SSCP analysis, the amplified DNAs were electrophoresed in 5\% acrylamide gels containing 5\% glycerol (Orita et al. 1989). DNA sequencing of aberrant bands was performed by the methods described above.

\section{Results}

cDNA cloning and homology search

In all, 89,903 base pairs of assembled DNA sequences derived from cosmids 581, 576, 425, and 566 (Fig. 1) were analyzed by GRAIL 2 (Xu et al. 1994). Of the 14 computerpredicted exonic fragments, 11 were scored as "excellent", one as "good", and two as "marginal". Using these possible exonic sequences, we performed exon-connection experiments and screened cDNA libraries. In this manner we obtained a cDNA sequence of 4536 nucleotides, which included 1581 bp of open reading frame encoding 527 amino acids. There was a polyadenylation signal, AATAAA, in the 3' non-coding region (4502-4507). The nucleotide sequence data will appear in the DDBJ/EMBL/Genbank nucleotide sequence databases with the accession number AB017642. Homology analysis of the predicted amino-acid sequence by the FASTA program revealed significant similarities to human Ste20/oxidant stress response kinase-1 (SOK1; 39\% identity in 414 amino acids) and MST1 (35\% identity in 384 amino acids) (Fig. 2). Both of these proteins are serine-threonine kinases. Since SOK1 is activated by oxidant stress, we named our gene OSR1 (oxidative-stress responsive gene 1 ).

\section{Northern-blot analysis}

Messenger RNAs isolated from various human tissues revealed a 4.6-kb transcript of OSR1 in all tissues examined (lung, kidney, colon, thymus, heart, liver, spleen, skeletal muscle, ovary, leucocyte, small intestine, testis, prostate, placenta, brain, and pancreas; Fig. 3). An additional, minor, transcript of $7.5 \mathrm{~kb}$ was detected in skeletal muscle and heart. However, as we isolated no cDNA clone corresponding to the minor transcript, it remains uncertain whether the slower band reflected a transcript generated from the same gene by alternative splicing or alternative poly(A), or a transcript of some related, cross-hybridizing gene.

\section{Determination of exon-intron junctions}

We defined the exon-intron junctions of the OSR1 gene (Table 1) by comparing cDNA sequences with genomic DNA sequences. The results indicated that it consists of 18 exons and spans a genomic region of about 90 kilobases, as 


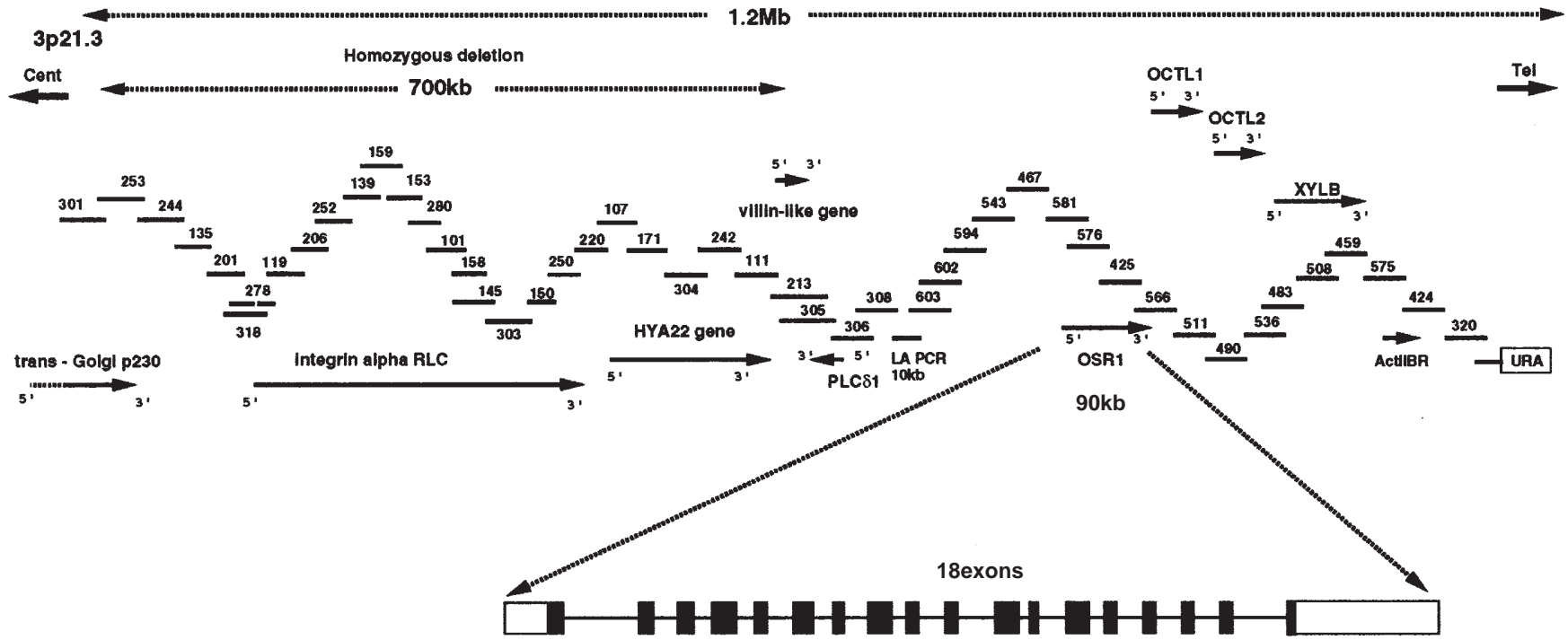

Fig. 1 Location of the novel gene (oxidative stress-resporsive gene 1; OSR1) and cosmid clones 581,576, 425, and 566 relative to eight other genes within or near the region at chromosome $3 \mathrm{p} 21.3$ that is homozygously deleted in some lung cancer cell lines. The genomic structure of

the gene is represented schematically; exons and introns are denoted by boxes and horizontal lines, respectively. Arrows indicate the transcriptional direction of each gene
Fig. 2 Homologies (black areas) between the predicted product of the OSR1 gene and human SOK1 and MST1 proteins

\begin{abstract}
OSR1 107 PRAAAAVMSM SEDS-SALPW SINRDDYELQ EMIGSGATAV VQAAYCAPKK EKVAIKRINL SOK1 1 MAHL RGFA-NQHSR VDPEELFTKL DRIGKGSFGE VYKGIDNHTK EWVAIKIIDL MST1 8 NPPRRQLKKL DEDSLTKQPE EV-..-FDVL EKLGEGSYGS VYKAIHKETG QIVAIKQVPV

OSR1 167 EKCQTSMDEL LKETRAMSQC HHPNIVSYYT SFVVKDELWL VMKLLSGGSV LDIIKHIVAK SOK1 55 EEAEDEIEDI OOEITVLSQC DSPYITRYFG SYLKSTKLWI IMEYLGGGSA LDLLK----MST1 68 E---SDLQEI IKEISIMOOC DSPHVVKYYG SYFKNTDLWI VMEYCGAGSV SDIIRL-.--

OSR1 227 GEHKSGVVDE STIATILREV LEGLEYLHKN GQIHRDVKAG NILLGEDGSV QIADFGVSAF SOK1 115 -.--PGPLEE TYIATILREI LKGLDYLHSE RKIHRDIKAA MVLLSEQGDV KLADFGVA-MST1 128 ---RNKTLTE DEIATILQST LKGLEYLHFM RKIHRDIKAG NILLNTEGHA KLADFGVAGQ

OSR1 287 LATGGDITRN EV-RKTFVGT POWMAPEVME ONRGYDFKAD IWSFGITAIE LATGAAPYHK $\begin{array}{lll}\text { SOK1 } & 175 & --- \text { GOLTDT OIKRNTFVGT PFWMAPEVIK Q-SAYDFKAD IWSLGITAIE LAKGEPPNSD } \\ \text { MST1 } & 188 \text { LTD----TMA K--RNTVIGT PFWMAPEVIQ EI-GYNCVAD IWSLGITAIE MAEGKRPYAD }\end{array}$

OSR1 347 YPPMKVLMLT LONDPPSLET GVQDKEMLKK YGKSFRKMIS LCLOKDPEKR PTAAELLRHK SOK1 235 LHPMRVLFLI PKNSPPTLE- G------Q HSKPPFEFVE ACLNKDPRFR PTAKELLKHK MST1 248 IHPMRAIFMI PTNPPPTFR- -.--KPEL-- WSDNFTDFVK QCLMKSPEDR ATATQLLOHP

OSR1 407 FFOK-AKNKE FLOEKTLQRA PTISERAKKV RRVPGSSGRL HKTEDGGWEN SDDEFDEESE SOK1 295 FITRYTKKTS FLTE-..-- - -LIDRYKRW K----SEG-- HGEESSS--- EDSDIDGEAE MST1 308 FVRS-AKGVS ILRD-LINEA MDV----KL KRQESQQREM DQDDEENSE- -EDEMDSGTM

OSR1 467 EGKAAISQLR SPRVKESISN SELFPTTDPV GTLLQVPEQI SAHLPQPAGQ IATQPTQVSL SOK1 355 DGEOGPIWTF PPTIRPS-PH SKL HK-..-- GTALHSSQK- .....-PADA VKROPRSQCL MST1 368 V-RAVGDEMG TVRVASTMTD GANTMIEHDD TL---PSQ-L GTMVINAEDE EEEGTMKRRD

OSR1 527 PPTAEPA--- -KTAQALSSG S-GSOETKIP ISLVLRLRNS KKELNDIRFE FTPGRDTAEG SOK1 415 STLVRPVFGE LKEKHKOSGG SVGALEELEN AFSLAEESCP GISDKLMVHL VERVQRFSHN MST1 428 ETMQPAKPSF LEYFEQKEKE NQINSFGKSV PGPLKNSSDW KIPQDGDYEF -LKSWTVE--
\end{abstract}

indicated in Fig. 1. All of the 14 exons predicted by the GRAIL 2 program were, in fact, transcribed into mRNA.

SSCP

To investigate the candidacy of this gene for involvement in carcinogenesis, we performed SSCP analysis to screen
DNAs isolated from human lung cancers for alterations in OSR1. An identical aberrant pattern was present in 4 of the 60 primary lung carcinomas examined. DNA sequencing of the PCR products disclosed a $\mathrm{C} \rightarrow \mathrm{T}$ transition at the second nucleotide of codon 304, which resulted in a substitution of isoleucine (ATA) for threonine (ACA). However, as this substitution was observed in the corresponding normal tissues and also in 1 of 55 normal control DNAs, we consid- 
Fig. 3 Multiple-tissue Northern blots of OSR1 cDNA. The main transcript, $4.5 \mathrm{~kb}$, is observed ubiquitously
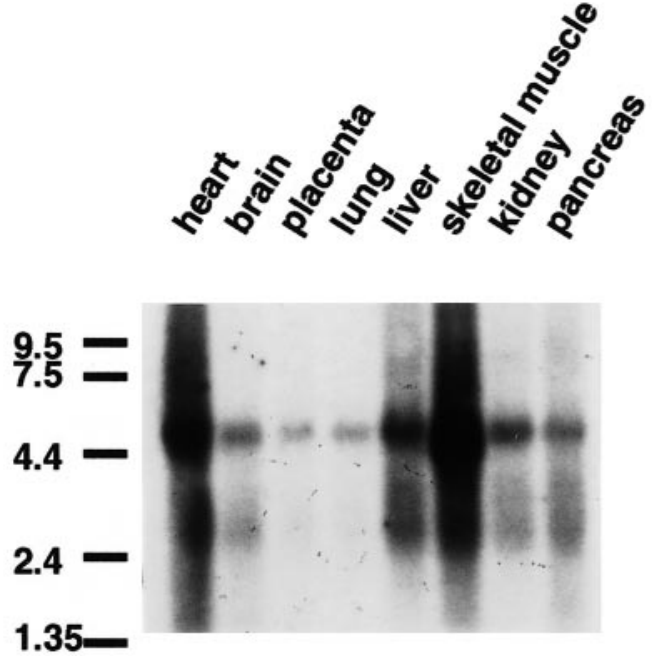
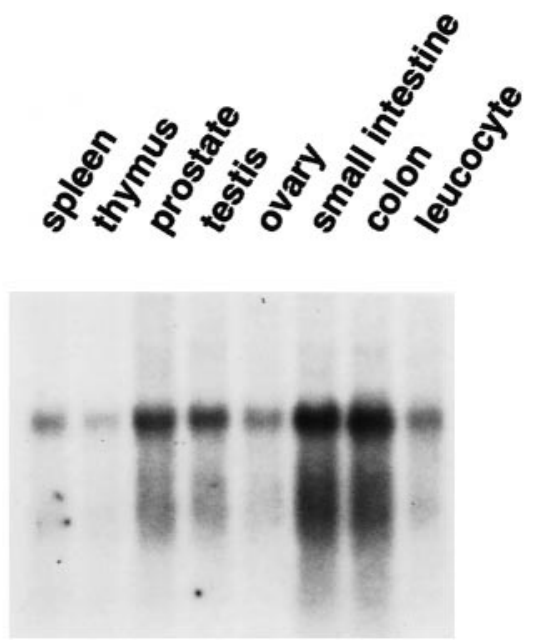

Table 1 Exon-Intron boundary sequences of the $O S R 1$ gene

\begin{tabular}{rrll}
\hline & $\begin{array}{l}\text { Exon length } \\
\text { (bp) }\end{array}$ & Splice acceptor & \\
\hline 1 & 412 & & Splice donor \\
2 & 113 & ttgttttagGGAGTGGAGC & GAGGTGATCGgtgagagcag \\
3 & 109 & ttcttgtagAAAGAAATC & CTAAGTCCTGgtatgcacat \\
4 & 142 & ctgtttcagGTTCTGTTCT & AGATCCACAGgtatgtaaaa \\
5 & 56 & tttttaaagAGATGTGAAA & CAGATTGCAGgtaatgatta \\
6 & 110 & tctatttcagACTTTGGGGT & TATGGAACAGgtaccgtgtc \\
7 & 102 & tgtttgcagGTCCGTGGTT & ACCAATGAAGgtgaggcttg \\
8 & 134 & attcttgcagGTTTTAATGC & CAGAAAAAAGgtaaaatatg \\
9 & 49 & ctggtttagACCAACAGCA & GAAAGCAAAGgtaggaaatt \\
10 & 66 & tcctctccagAATAAAGAAT & AGCAAAAAAGgtaaatcaga \\
11 & 123 & taatgagcagGTTCGGAGAG & ACAACTCAGGgtaaattta \\
12 & 36 & tttgttagTCTCCCCGAG & AAATTCTGAGgtaagtaatt \\
13 & 147 & tgcttttagGCTTTGTCTT & AACAGCTCAGgtaaagccgg \\
14 & 65 & tttgttacagCTCTTTCCAA & TAAGATTAAGgtaagtagac \\
15 & 53 & gaattccaaAAAGAACTAA & CCTGGGAGAGgtgaggcatc \\
16 & 69 & gtccttgcagATACAGCAGA & TTAGTAATGgtaactccat \\
17 & 65 & atgattacagTGGCAGCTAA & TTTCAAACTGgtactcatcc \\
18 & 2668 & tggttttagGCATCTGGTG & GTAAATTGTCcttagtggtg \\
\hline
\end{tabular}

The accession number of the OSR1 cDNA sequence is AB017642

OSR1, Oxidative stress-responsive gene 1

ered it to reflect a rare polymorphism not associated with cancer.

\section{Discussion}

We have reported here the isolation of the cDNA, and characterization of the complete genomic structure, of a novel gene encoding a protein with significant similarity to SOK1 (Ste20/oxidant stress response kinase-1) and MST1. SOK-1, a human Ste20-like kinase from the germinal center (GC) kinase group, functionally resembles the yeast Ste20 proteins that transduce signals in response to environmental stress. However, SOK1 is not involved in the generalized stress response pathway that is stimulated by growth fac- tors, alkylating agents, cytokines, or environmental situations such as heat shock and osmolar stress. It is activated relatively specifically by oxidant stress, although it does not activate any of the known mitogen activated protein (MAP) kinase cascades (Creasy and Sheriff 1995; Pombe et al. 1996). MST1, although it is homologous to a member of a yeast mitogen activated protein kinase (MAPK) cascade, is not involved in regulating any mammalian MAPK pathway; this kinase potentially regulates a novel signaling cascade (Creasy et al. 1996).

We designated the novel gene reported here as OSRI (oxidative-stress responsive gene 1), because, on the basis of its significant similarity to SOK1, it may be involved specifically in the response to oxidative stress. Characterization of the genomic structure of $O S R 1$ should contribute to investigations concerned with divergence or evolution among the 
SOK1 family of kinases.

Since the OSR 1 gene is located in the close vicinity of the region that is homozygously deleted in several lung cancer cell lines, we consider it to be a candidate tumor suppressor. However, our failure to find mutated forms of this gene in any of 60 primary lung carcinomas examined makes it quite unlikely that $O S R 1$ plays any carcinogenic role in the lung itself.

Acknowledgments This work was supported in part by a special grant for Strategic Advanced Research on Cancer from the Ministry of Education, Culture, Sports, and Science of Japan; and by a Research for the Future Program Grant of The Japan Society for the Promotion of Science.

\section{References}

Creasy CL, Sheriff J (1995) Cloning and characterization of a human protein kinase with homology to Ste20. J Biol Chem 270: 2169521700

Creasy CL, Ambrose DM, Chernoff J (1996) Ste20-like protein kinase, Mst1, dimerizes and contains an inhibitory domain. J Biol Chem 271: 21049-21053

Hibi K, Takahashi T, Yamakawa K, Ueda R, Sekido Y, Ariyoshi Y, Suyama M, Takagi H, Nakamura Y, Takahashi T (1992) Three distinct regions involved in $3 p$ deletion in human lung cancer. Oncogene 7: 445-449

Ishikawa S, Kai M, Tamari M, Takei Y, Kuwata K, Takeuchi K, Bandou H, Yamane Y, Ogawa M, Nakamura Y (1997a) Sequence analysis of a $685-\mathrm{kb}$ genomic region on chromosome 3p22-p21.3 that is homozygously deleted in a lung carcinoma cell line. DNA Res 4: $35-43$
Ishikawa S, Takahashi T, Ogawa M, Nakamura Y (1997b) Genomic structure of the human PLCD1 (phospholipase C delta) locus on 3p22-p21.3. Cytogenet Cell Genet 78: 58-60

Ishikawa S, Kai M, Murata Y, Tamari M, Daigo Y, Murano T, Ogawa M, Nakamura Y (1998) Genomic organization and mapping of the human activin receptor type IIB (hActR-IIB) gene. Jpn J Hum Genet 43: 132-134

Murata Y, Tamari M, Takahashi T, Horio Y, Hibi K, Yokoyama S, Inazawa J, Yamakawa K, Ogawa A, Takahashi T, Nakamura Y (1994) Characterization of an 800-kb region at 3p22-p21.3 that was homozygously deleted in a lung cancer cell line and construction of a cosmid contig. Hum Mol Genet 3: 1341-1344

Nishiwaki T, Daigo Y, Tamari M, Fujii Y, Nakamura Y (1998) Molecular cloning, mapping, and characterization of two novel human genes, OCTL1 and OCTL2, bearing homology to organic-cation transporters. Cytogenet Cell Genet (in press)

Orita M, Suzuki S, Sekiya T, Hayashi K (1989) A rapid and sensitive detection of point mutations and polymorphisms using the polymerase chain reaction. Genomics 5: 874-879

Pombe CM, Bonventre JV, Molnar A, Kyriakis J, Force T (1996) Activation of a human Ste20-like kinase by oxidant stress defines a novel stress response pathway. EMBO J 15: 4537-4546

Tamari M, Daigo Y, Ishikawa S, Nakamura Y (1998) Genomic structure of a novel human gene on chromosome 3p22-21.3 encoding a xylulokinase-like protein. Cytogenet Cell Genet 82: 101-104

Yamakawa K, Morita R, Takahashi E, Hori T, Ishikawa J, Nakamura Y (1991) A detailed deletion mapping of the short arm of chromosome 3 in sporadic renal cell carcinoma. Cancer Res 51: 4707-4711

Yamakawa Y, Takahashi T, Horio Y, Murata Y, Takahashi E, Hibi K, Yokoyama S, Ueda R, Takahashi T, Nakamura Y (1993) Frequent homozygous deletions in lung cancer cell lines detected by a DNA marker located at 3p21.3-p22. Oncogene 8: 327-330

Yokoyama Y, Yamakawa K, Tsuchiya E, Murata M, Sakiyama S, Nakamura Y (1992) Deletion mapping on the short arm of chromosome 3 in squamous cell carcinoma and adenocarcinoma of the lung. Cancer Res 52: 873-877

$\mathrm{Xu}$ Y, Mural RJ, Uberbacher EC (1994) Constructing gene models from accurately predicted exons; an application of dynamic programming. Comput Appl Biosci 10: 613-623 